\title{
Building energy performance assessment for existing commercial buildings with heritage values
}

\author{
James Pow Chew Wong* \\ RMIT University, Melbourne, Australia
}

\begin{abstract}
The building sector accounts for 19\% of Australia's energy consumption and around $23 \%$ of the greenhouse gas emissions. In 2005, commercial buildings in Australia were responsible for $10 \%$ or 26 megatonnes $(\mathrm{Mt})$ of the nation's greenhouse gas emissions. They are two effective ways to reduce the building sector's emissions, namely constructing new energy efficient buildings or retrofitting existing buildings. Due to the life expectancy of existing building stock the greatest reduction in emissions before 2030 could be achieved through retrofits. Building performance assessment and evaluation uses predictive modelling method to investigate and evaluate building performance in energy demands, thermal occupant comfort, indoor air quality, building retrofit options and many other related environmental and wellbeing aspects. This paper discussed the use of building performance simulation software to investigate the impacts of various retrofit options have onto energy performance of existing commercial buildings with heritage values in Australia. The research explores the use of thermal and airflow modelling in assisting understanding of building energy performance with various retrofit options applied to existing commercial buildings. The finding highlights the capabilities of building performance simulation software in decision making for building performance investigations.
\end{abstract}

\section{Introduction}

The building sector contributed to around 19\% of Australia's energy consumption and around $23 \%$ of the greenhouse gas (GHG) emissions [1]. Commercial buildings in Australia contributed to around $10 \%$ or 26 megatonnes (Mt) of the nation's GHG emissions in 2005. The Centre for International Economics has noted that energy end use for the commercial sector has nearly tripled since the 1970s [2].

A number of publications highlight the need for more comprehensive information with respect to existing non-domestic building stock typology, distribution and energy use in order to inform future policy formulation $[3,4]$. Research has shown that energy consumption in commercial buildings is complex due to the wide range of building fabrics and mechanical systems employed $[1,5,6,7]$.

\footnotetext{
* Corresponding author: james.wong@rmit.edu.au
} 
Energy modelling was used to explore the operational energy use of the case study buildings in their existing state (base case) and in case when energy efficiency measures through selected retrofits were implemented. The findings of this study may therefore inform a better understanding of the challenges involved in analysing the energy demand of commercial buildings with heritage value. This paper investigates the energy performance for two case study buildings with selected retrofits' impacts. The paper also attempts to identify lessons learnt and strategies that could be used to improve building simulation results in the future.

\section{Research investigation and modelling methods}

Two case study buildings with heritage value were selected from buildings constructed between the 1900s and the 1930s. The first case study is the Old Attorney-General's Building in Adelaide, South Australia. The building was built in the 1900s and consists of an original stone and brick structure with covered verandas, as well as a more modern addition towards the north. The building consists of two-storey with a gross floor area of $1195 \mathrm{~m} 2$. The second case study, the AMP Building in Townsville, Queensland, is a fivestorey building, built in the early 1930's in a classical style. Still displaying its original and unchanged design, it is an important landmark in one of Townville's main streets. Table 1 summaries the characteristics of the two case study buildings. The two case study buildings are selected based on their representativeness of the heritage building type in their regions and periods, the climatic conditions the buildings are located (with Adelaide located in a warm temperate climate and Townsville located in a climate with high humidity during summer and warm winter), and the main building walls' constructions which represented the common heritage building types in Australia.

Table 1. Case study buildings' characteristics.

\begin{tabular}{|c|l|c|c|c|c|c|c|c|}
\hline Case Study & Era & $\begin{array}{c}\text { Gross } \\
\text { Floor } \\
\text { Area, } \\
\mathrm{m}^{2}\end{array}$ & $\begin{array}{c}\text { Net } \\
\text { Lettable } \\
\text { Area, } \mathrm{m}^{2}\end{array}$ & $\begin{array}{c}\text { Number } \\
\text { of } \\
\text { Storeys }\end{array}$ & Roof & Glazing & Walls & $\begin{array}{c}\text { Skylig } \\
\text { ht }\end{array}$ \\
\hline $\begin{array}{c}\text { Old } \\
\text { Attorney- } \\
\text { General's } \\
\begin{array}{c}\text { Building, } \\
\text { Adelaide }\end{array}\end{array}$ & $1900 \mathrm{~s}$ & 1195 & 894 & 2 & $\begin{array}{c}\text { Pitch } \\
\text { and } \\
\text { flat }\end{array}$ & $\begin{array}{c}\text { Single } \\
\text { clear } \\
\text { float }\end{array}$ & $\begin{array}{c}\text { Bluestone } \\
\text { brick and } \\
\text { brick } \\
\text { cavity }\end{array}$ & $\begin{array}{c}\text { Single } \\
\text { glazed }\end{array}$ \\
\hline $\begin{array}{c}\text { AMP } \\
\text { Building, } \\
\text { Townsville }\end{array}$ & $1930 \mathrm{~s}$ & 1289 & 915 & 5 & $\begin{array}{c}\text { Pitch } \\
\text { and } \\
\text { flat }\end{array}$ & $\begin{array}{c}\text { Single } \\
\text { clear } \\
\text { float }\end{array}$ & $\begin{array}{c}\text { Uninsulat } \\
\text { ed brick } \\
\text { cavity }\end{array}$ & None \\
\hline
\end{tabular}

The research used a whole building dynamic simulation software called IESVE for Engineers by Integrated Environmental Solutions [8] to predict the annual electricity and gas usage for the case study buildings. The software takes into account the weather data for the building's geographical location, its three-dimensional geometry, the thermal performance of the building envelope, the type and efficiencies of the heating and cooling systems, hot water systems as well as internal heat gains due to appliances, lightings and occupants.

\subsection{Data collection}


The building stakeholders were contacted to obtain and confirm key information on the case study buildings' geometry, layouts, construction materials, heating and cooling systems, fuels used, etc. Comprehensive information such as building plans, building operational and usage patterns, fixed appliances used, heating and cooling systems installed was obtained. A Quantity Surveyor consultant was also engaged to determine the construction types and the nature of the materials used when these information are not available. The accuracy of the input information is critical as the accuracy of building energy simulation predictions is largely dependent on it.

\subsection{3-D modelling}

ModelIT, which is a module of the IESVE for Engineers package, allows the operator to construct three-dimensional models of buildings. Virtual models are usually constructed floor-by-floor using this module. Figures 1 and 2 shows the case study buildings as modelled in the IESVE for Engineers software. Building specific construction elements such as external walls and floors were constructed using the software's building materials database according to the specifications provided by the Quantity Surveyor using the module. In Australia, solar heat gain coefficient (SHGC) is used in the glazing industry rather than Shading Coefficient (SC). SC may be converted to SHGC by multiplying the value by 0.87 [9].

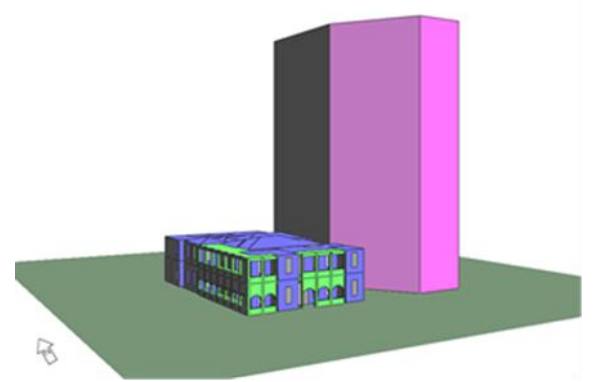

Fig. 1. Model image of the Old AttorneyGeneral's Building in Adelaide.

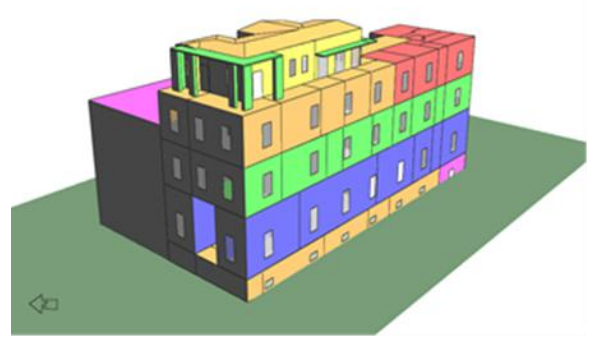

Fig. 2. Model image of the AMP Building in Townsville.

While the software allowed the customisation of operational profiles, the usage profiles for occupancy, lighting and equipment for the modelling were based on the schedules of the NABERS Energy-Guide to Energy Estimation for Computer Simulations due to some of the building specific information was not available [10]. The default occupant density is 1 occupant per $15 \mathrm{~m}^{2}$ of office space and a sensible heat gain of $75 \mathrm{~W} /$ person. The values of internal heat gains due to equipment, occupancy and lighting were subsequently adjusted in the input of the modelling in order to reflect the actual conditions in the case study buildings.

The type and efficiency of the HVAC systems used in the case study buildings were assumed based on research carried out in similar types of buildings due to lack of information of the buildings' operational systems. It was assumed that spaces were conditioned by an inefficient central HVAC fan coil system based on the heritage nature of the case study buildings. The set point for space heat is controlled at $19^{\circ} \mathrm{C}$ and it was assumed natural gas was used. The cooling set point is controlled at $23^{\circ} \mathrm{C}$ and assumed electricity was used at the central air-conditioning plant. The temperature setting of $19^{\circ} \mathrm{C}$ for heating and $23^{\circ} \mathrm{C}$ for cooling were considered a reasonable assumption as they fall within the temperature range of $18^{\circ} \mathrm{C}$ to $26^{\circ} \mathrm{C}$, which is a standard parameter used to model air-conditioned reference buildings according to the Building Code of Australia Section 
JV3 [11]. The IESVE for Engineers software assumed the temperature sensor for its HVAC systems at the centre of the space/room for simulation purposes. Constant efficiencies were assumed for both the heating and cooling systems. External climatic data was modelled by the software using real data from the nearest weather station.

SunCast and MacroFlo are additional modules of the IESVE for Engineers software, which are able to take account of the effects of solar shading and of natural ventilation in the dynamic simulation. The SunCast module manages the impact of the shading provided by neighbouring buildings and building integrated shading on the energy demand of the building. SunCast considers the date, time, orientation, as well as the site latitude and longitude. Daylighting effects on lighting use and subsequent impacts were not included in the simulations. The effects of trees and their shadows were not considered.

After all parameters had been assigned to the building model, the dynamic thermal simulation was run using ApacheSim module. A simulation period of 365 days with a simulation time step of 10 minutes as recommended by the IESVE software guidelines was used [8], and with a preconditioning period of 10 days.

\subsection{Building retrofit interventions}

One of the goals of the study was to identify and review a range of suitable design solutions that could be used to reduce the environmental impacts of heritage commercial buildings. A range of intervention possibilities were considered, including adding insulation, refurbishing existing windows, installing secondary or double glazing, applying ultraviolet (UV) film, upgrading heating, ventilation, and air conditioning (HVAC) systems and lighting systems, etc.

There are a total of 16 intervention strategies applied to the case study buildings for the project but this paper only report on the top five (5) interventions that have the most significant impacts on the energy performance of the case study buildings. The top five interventions applied to the case study buildings for investigations are chiller upgrade, changing cooling set point to $26^{\circ} \mathrm{C}$, lighting upgrade, switching off equipment after office hours, opening windows and increase cooling set point to $26^{\circ} \mathrm{C}$. As the Old AttorneyGeneral's Building is not possible to implement opening windows as an intervention option, therefore intervention in changing the cooling set point to $26^{\circ} \mathrm{C}$ is selected.

\section{Results and discussions}

The Old Attorney General's Building in Adelaide is assumed to be conditioned by a central HVAC fan coil system. Space heating is assumed to be provided by a central boiler fuelled by natural gas. Cooling is assumed to be provided by a central air-conditioning plant fuelled by electricity. Hot water is assumed to be provided by an electric system. The AMP Building is assumed to be conditioned by a central HVAC fan coil system. Space heating and hot water is assumed to be provided by a central boiler fuelled by natural gas. Cooling is assumed to be provided by a central air-conditioning plant fuelled by electricity.

Figures 3 and 4 below show the IESVE for Engineers operational energy simulation results for the buildings. Both electricity and lighting usage were found to be account for a quarter each of the building's energy consumption, with equipment constitute a third of the energy demand for the Old Attorney-General's building. Electricity usage constitutes almost half of the building's energy consumption, followed by lighting and equipment which constitute around $22 \%$ of the energy demand for the AMP building. 


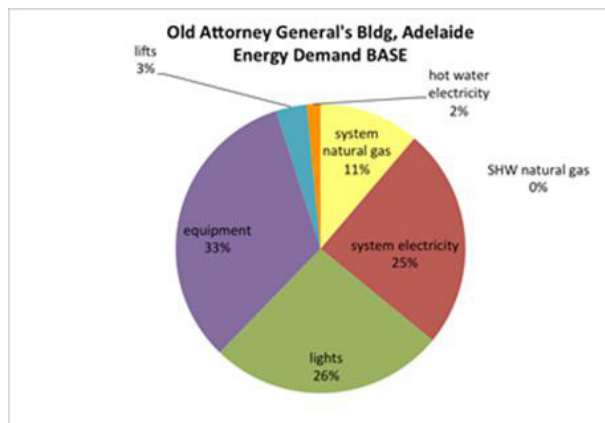

Fig. 3. Operational energy simulation results for Old Attorney-General's Building.

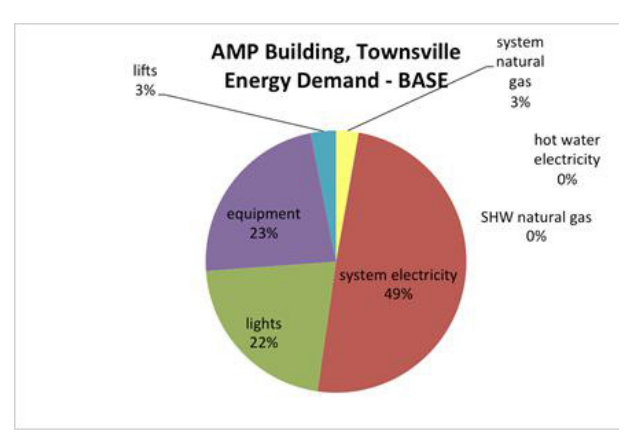

Fig. 4. Operational energy simulation results for AMP Building.

For the case study buildings considered, life cycle global warming impact was predominantly caused by cooling (25\%-49\%), lighting (22\%-26\%) and equipment use (23\%-33\%). Other operational elements of heating (3\%-11\%) and lifts $(3 \%)$ represented smaller portions of the life cycle impact. Collectively, this result shows that intervention initiatives that target cooling, lighting and equipment are likely to generate the most significant results.

For the chiller upgrade intervention, information on the efficiencies of the HVAC systems is not provided. Therefore educated estimates were taken for these values. Both buildings were assumed to be equipped with a central fan coil system and cooled by electricity. In this intervention the efficiency of the chiller system is assumed to be increased from a Nominal EER (Energy Efficiency Ratio) of 3.13 to between 4.38 and 5.50.

In the changing cooling set point to $26^{\circ} \mathrm{C}$ intervention, the cooling set point was assumed to be set at $23^{\circ} \mathrm{C}$ under the base case. In this intervention, it was examined how the energy use would change if the cooling started operating at a temperature which was three degrees higher, at $26^{\circ} \mathrm{C}$.

For the lighting upgrade intervention, both buildings were assumed to be equipped with T8 light fittings in the base cases. In the lighting intervention, it was assumed that all lamps would be replaced by the more energy efficient T5 lighting.

For the switching off equipment after office hours intervention, while the number of computers and their sensible gain values remain the same in this intervention as in the base case scenarios, the variation profile of the computers has been changed. In the base case, the National Australian Built Environment Rating System (NABERS) Appliances and Equipment profile was used.

In the opening windows and increase cooling set point to $26^{\circ} \mathrm{C}$ intervention, according to the information provided, in both buildings, the windows are kept closed throughout the year. This intervention examines the effect of natural ventilation on the energy demand of the buildings. In this intervention, the opening of half of the windows between 7:00 $\mathrm{h}$ and 21:00 $\mathrm{h}$ on weekdays if the room air temperature is between $23^{\circ} \mathrm{C}$ and $26^{\circ} \mathrm{C}$. In addition, the chiller's set point is increased to $26^{\circ} \mathrm{C}$. In other words, the occupants of the building are assumed to open the windows when the room reaches $23^{\circ} \mathrm{C}$, and they are assumed to close them again, when the inside temperature reaches $26^{\circ} \mathrm{C}$. Only then will the air conditioning switch on. Instead of setting the comfort level at $23^{\circ} \mathrm{C}$, as in the base case, the comfort level is shifted to $26^{\circ} \mathrm{C}$. 
Table 2. Thermal modelling results for the case study buildings.

\begin{tabular}{|c|c|c|c|c|c|c|c|}
\hline & & & & $\mathrm{ACH}$ & ESIM & RESU & TSS \\
\hline & 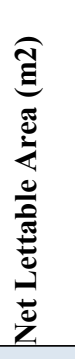 & 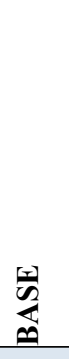 & 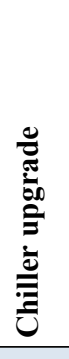 & 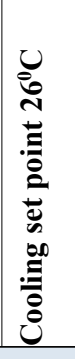 & 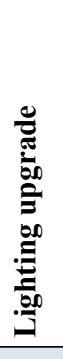 & 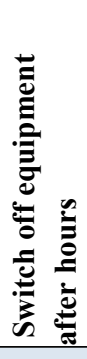 & 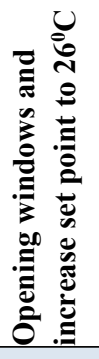 \\
\hline Natural Gas Use (MJ/n & n2.yea & & & & & & \\
\hline AMP, Townsville & 915 & & & Not ce & onnec & ed to $g$ & \\
\hline $\begin{array}{l}\text { Old Attorney General's } \\
\text { Buildings, Adelaide }\end{array}$ & 894 & 93 & 93 & 93 & 112 & 113 & 122 \\
\hline Electricity Use (kWh/n & 12.yea & & & & & & \\
\hline AMP, Townsville & 915 & 249 & 208 & 220 & 223 & 215 & 219 \\
\hline $\begin{array}{l}\text { Old Attorney General's } \\
\text { Buildings, Adelaide }\end{array}$ & 894 & 206 & 192 & 191 & 182 & 168 & 194 \\
\hline
\end{tabular}

Table 2 above shows the thermal modelling results for the base case and the top interventions for the two case study buildings. Gas usage was mainly higher for most of the interventions for Old Attorney-General's Building but electricity usage saw saving up to $16 \%$.

\section{Conclusion}

Building operational requirements were found to be driven predominantly by cooling, lighting and equipment use. The large contribution of operation was explored further by implementing building interventions that sought to reduce impacts. Operational heating and cooling (system natural gas and system electricity) contributed the most to the total operation energy usage for the case study buildings. Equipment and lighting contributed around a quarter each to the total annual operational energy usage. The case study buildings performed quite satisfactory in terms of operational energy usage compared to the average commercial buildings in Australia.

A number of building interventions were explored, each of which was intended to reduce building energy use in operation. The results demonstrated that significant improvements in building life cycle global warming impacts could be achieved. For the case study buildings considered, when applied in isolation, high impact outcomes tended to be associated with building equipment use, lighting and mechanical systems. Occupant related interventions, such as switching off equipment after hours and on weekends was particularly effective. Efficiency upgrades such as upgrading lighting systems and the building chiller were also effective.

\section{Acknowledgments}


The author would like to thank the Department of Planning and Community Development of the State of Victoria, the Heritage Chairs and Officials of Australia and New Zealand (HCOANZ) and the research team at RMIT University for assisting and supporting this research project and subsequent publication of the findings.

\section{References}

1. DCCEE 2010 The Pathway to 2020 for Low-Energy, Low-Carbon Buildings in Australia: Indicative Stringency Study (Canberra: Department of Climate Change \& Energy Efficiency)

2. Centre for International Economics 2007 Capitalising on the building sector's potential to lessen the costs of a broad based GHG emissions cut (Canberra: Centre for International Economics)

3. Bruhns H 2008 Identifying determinants of energy use in the UK nondomestic stock Proc. $5^{\text {th }}$ Int. Conf. on Improving Energy Efficiency in Commercial Buildings (Frankfurt) (Joint Research Centre, Institute for Energy, European Commission) pp 389-400

4. Lam J C 2000 Energy analysis of commercial buildings in subtropical climates Building and Environment 35 pp 19-26

5. DEWHA 2008 Mandatory Disclosure of Commercial Building Energy Efficiency: Concept Report (Canberra: Department of the Environment Water Heritage and the Arts)

6. Kofoworola O F and Gheewala S H 2009 Life cycle energy assessment of a typical office building in Thailand Energy and Buildings 41 pp 1076-1083

7. Haase M, Grini C and Wigenstad T 2010 Measurement and simulation of a commercial building in Norway Proc. 6th Int. Conf. on Improving Energy Efficiency in Commercial Buildings (Frankfurt) (Luxembourg: Joint Research Centre, Institute for Energy, European Commission) pp 416-429

8. IES 2010. ApacheSim User Guide. IES Virtual Environment 6.4, Integrated Environmental Solutions Limited.

9. ASHRAE Handbook Fundamentals 2009. American Society of Heating, Refrigerating and Air- Conditioning Engineers, Inc.

10. Department of Environment, Climate Change and Water 2009 NABERS Energy Guide to Building Energy Estimation (Sydney: Department of Environment, Climate Change \& Water)

11. ABCB 2010 Handbook on BCA Section $J$ - Assessment and Verification of an Alternative Solution (Australian Government and States and Territories of Australia) 